\title{
Comparison of Content Based Image Retrieval Systems Using Wavelet and Curvelet Transform
}

\author{
Suchismita Das $^{\# 1}$, Shruti Garg ${ }^{* 2}$, G. Sahoo ${ }^{\# 3}$ \\ ${ }^{\#}$ Department of Computer Science and Engineering \\ Birla Institute of Technology, Mesra, Ranchi, India \\ ${ }^{1}$ sd.suchilgmail.com \\ ${ }^{3}$ gsahoo@bitmesra.ac.in \\ *Department of Computer Science and Engineering \\ Birla Institute of Technology, Mesra, Ranchi, India \\ ${ }^{2}$ gshruti_garg@yahoo.com
}

\begin{abstract}
The large numbers of images has posed increasing challenges to computer systems to store and manage data effectively and efficiently. This paper implements a CBIR system using different feature of images through four different methods, two were based on analysis of color feature and other two were based on analysis of combined color and texture feature using wavelet coefficients of an image. To extract color feature from an image, one of the standard ways i.e. color histogram was used in YCbCr color space and HSV color space. Daubechies' wavelet transformation and Symtel's wavelet transform were performed to extract the texture feature of an image. In this paper a color image retrieval system is illustrated, in which the novelty lies in the use of a fuzzy partition of the HSV color space and wavelet transformation of the fuzzified new image. To increase efficiency of the system finally an image retrieval method was proposed using curvelet transform of an image, which provides an opportunity to extract more accurate texture feature for image retrieval. After obtaining all experimental results, a comparative study was done. From the result it was inferred that curvelet based method gave a better performance as compared to other methods.
\end{abstract}

Keywords- CBIR, wavelet transformation, Color histogram, YCbCr, HSV, curvelet transform

\section{INTRODUCTION}

Now days, CBIR (content based image retrieval) is a hotspot of digital image processing techniques. CBIR research started in the early 1990's and is likely to continue during the first two decades of the 21st century [1]. There is a growing interest in CBIR because of the limitations inherent in metadata-based systems, as well as the large range of possible uses for efficient image retrieval. The Content Based Image Retrieval System (CBIR) also known as query by image content (QBIC) and content-based visual information retrieval (CBVIR) is a system. The term 'content' in this context might refer to colors, shapes, textures, or any other information that can be derived from the image itself. Content based image retrieval (CBIR) is therefore proposed, which finds images that have visual low-level image features similar to those of the query image example [2].

There are two approaches to image retrieval: Text-Based approach and Content-Based approach. Text-Based approach has some obvious shortcomings as each person can have different perception for each textual description. It is also time consuming when dealing with very large databases. Content based retrieval of visual data requires a paradigm that differs significantly from both traditional databases and text based image understanding systems [2]. Content based 
The International Journal of Multimedia \& Its Applications (IJMA) Vol.4, No.4, August 2012

image retrieval (CBIR) is a way to get around these problems. "Content-based" means that the search will analyze the actual contents of the image rather than the metadata such as keywords, tags, and/or descriptions associated with the image.

Feature extraction is very crucial step in image retrieval system to describe the image with minimum number of descriptors. The basic visual features of images include color and texture [3]. The color gives user a feel in terms of visual similarity but the texture does not give much of visual feel but it helps to retrieve [4] based on patterns / textures [5],[6]. The histogram is the most commonly used structure to extract the color component of an image [2]. The conventional color histogram $(\mathrm{CCH})$ of an image indicates the frequency of occurrence of every color of in an image [7]. Texture is another important property of images. Various texture representations have been investigated in pattern recognition and computer vision. Wavelet transformations were the most useful technique to extract the texture feature of an image.

HSI color space was characterized into dominant color bins and by using a specific fuzzy similarity measure. The RGB color space (Red, Green, Blue) is widely used to represent colors, e.g. on computer screens. However, for color image retrieval purposes it is more convenient to use a color model that characterizes color with one dimension instead of three [8]. Therefore, the HSI color space is preferred.

$\mathrm{Ni}$ and Leng attempted an initial application of curvelet on color image retrieval, but it was not implemented properly and no meaningful result was reported. In their work, no benchmark image database is used, no retrieval accuracy was reported and there was no comparison with other techniques [9] [10]. Hence this paper puts forward an improved method based on curvelet transform. In this paper the curvelet transformation was performed to extract the texture feature of an image during image retrieval and this technique was compared with color based retrieval as well as wavelet transform based image retrieval techniques.

In CBIR each image that is stored in the database has its features extracted and compared to the features of the query image [7]. CBIR systems can also make use of relevance feedback, where the user can progressively refines the search results by marking images in the results. The system was implemented in following two steps:

\section{A. Feature Extraction}

The first step is to extract the visual low level features of an image to a distinguishable extent.

\section{B. Similar Measurement}

The second step performs the matching of the features obtained by step 1 to the features of query image yield a result that is visually similar.

\section{PROPOSED SCHEMES}

In this paper four methods of image retrieval were proposed, out of which two were based on color feature of an image and other two were based on combined color and texture feature of an image.

\section{A. Image Retrieval System Based on Color Feature}

Content based image retrieval system based on color similarity is achieved by computing a color histogram for each image that identifies the proportion of pixels having specific values within an image (that humans express as colors). The proposed color based image retrieval technique is a certain modification of the methods referred in [1]. 


\section{1) System Using HSV Color Model}

The input images to the system were in RGB color format. After resizing it, next step is the conversion of the color-space of the image. The color-space of the image is changed from RGB to Hue Saturation Value (HSV). In the HSV color space each pixel contributes its hue and intensity based on its saturation. The generated histogram consists of "true color" components and "gray color" components, which store contributions from the hue and the intensity of each pixel. As hue varies from 0 to 360 degree, the corresponding colors vary from red through yellow, green, cyan, blue, magenta, and black to red. As saturation varies from 0 to 1.0 , the corresponding colors (hues) vary from unsaturated (shades of gray) to fully saturated (no white component). As value, or brightness, varies from 0 to 1.0 , the corresponding colors become increasingly brighter.

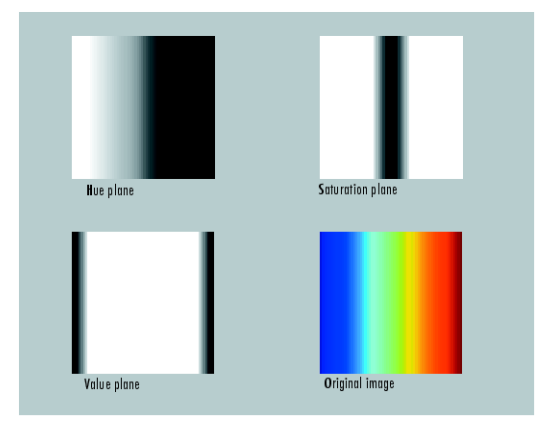

Fig.1 The different planes of HSV color space.

\section{2) System Using YCbCr Color Model}

The more frequently adopted approach for CBIR systems is based on the conventional color histogram $(\mathrm{CCH})$, which contains occurrences of each color in a particular color space obtained counting all image pixels having that color. The most common color representation model is RGB color model in which colors are represented as a combination of various intensities of red, green, and blue. Another color space, widely used for digital image and video is the $\mathrm{YCbCr}$ color space (also known as YUV).In this color space luminance (brightness or intensity) information is stored as a single component (Y). Chrominance (color) information is stored as two colordifference components $(\mathrm{Cb}$ and $\mathrm{Cr})$. $\mathrm{Cb}$ represents the difference between the blue component and a reference value. Cr represents the difference between the red component and a reference value.

Comparing all the colors between two images would be very time consuming and complex. So reducing the amount of information is performed by quantizing the color distribution into color histograms. When computing a color histogram for an image, the different color axes are divided into a number of so-called bins [7]. 
The International Journal of Multimedia \& Its Applications (IJMA) Vol.4, No.4, August 2012

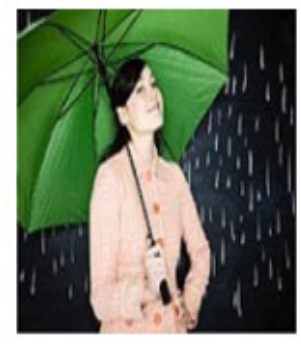

Fig.2(a).Image in RGB color space

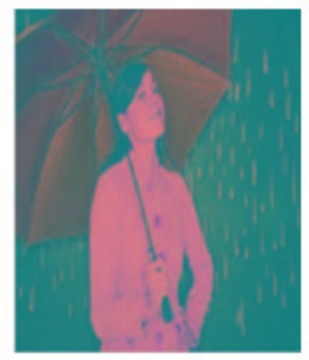

Fig.2(b). Image in $\mathrm{YCbC}$ color space

\section{3) Algorithm for color based image retrieval}

The steps involved in color based image retrieval are given below:

Step 1:

Preprocessing: Each image of the database was resized to a fixed size of $160 \times 120$ pixels.

Step2:

Each image of the database was then converted to $\mathrm{HSV} / \mathrm{YCbCr}$ color space.

Step3:

Color histogram $(\mathrm{CCH})$ was computed for each of the three planes and Quantization wperformed. Color histogram was computed by joint probabilities of intensities of the color channels. The color histogram can be thought of as a set of vectors.

More formally, the color histogram is defined by,

$\mathrm{h}_{\mathrm{A}, \mathrm{B}, \mathrm{C}}(\mathrm{a}, \mathrm{b}, \mathrm{c})=\mathrm{N} . \operatorname{Prob}(\mathrm{A}=\mathrm{a}, \mathrm{B}=\mathrm{b}, \mathrm{C}=\mathrm{c})$

Where $\mathrm{A}, \mathrm{B}$ and $\mathrm{C}$ represent the three color channels ( $\mathrm{HSV}$ or $\mathrm{YCbCr}$ ) and $\mathrm{N}$ is the number of pixels in the image [2].

Step 4:

The standard deviation was computed for each histogram. A feature vector was formed based on these values of standard deviation which was used during image retrieval process for similarity measure.

The standard deviation value was calculated as:

$$
S=\sqrt[2]{\left(\frac{1}{m} \sum\left(x_{i}-\bar{x}\right)^{2}\right)}
$$

Where,

$$
\mathrm{X}=\frac{1}{m} \sum_{\mathrm{i}=1}^{\mathrm{m}} \mathrm{x}_{\mathrm{i}}
$$

Where, $\mathrm{m}=$ No. of elements in the sample.

\section{B. Image Retrieval System Based on Color and Texture Feature}

A very basic issue in designing a CBIR system is to select the most effective image features to represent image contents [11]. Texture is a difficult concept to represent; it can be represented either as statistical measure or as wavelets. In present paper content based image retrieval system was designed by combining both color and texture. Here texture was represented using wavelet coefficients. This was a certain alteration of the method proposed in [12] for texture feature and in [1] for color feature extraction. 
The International Journal of Multimedia \& Its Applications (IJMA) Vol.4, No.4, August 2012

Mathematically, wavelet transform is a convolution operation, which can equivalent to passing the pixel values of an image through a low pass filter and a high pass filter. Although suggested by some researchers and are easier to implement, Haar wavelets do not have sufficiently sharp transition and hence are not able to separate different frequency bands appropriately [6]. Daubechies' wavelets, on the other hand, have better frequency resolution properties because of their longer filter lengths [6].

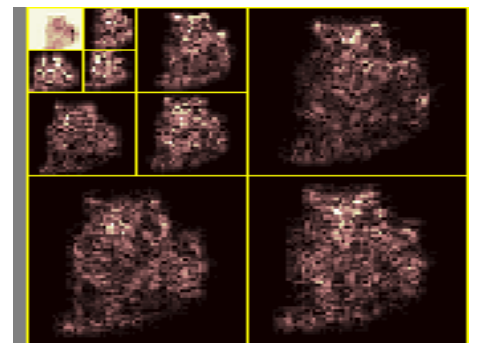

\begin{tabular}{|c|c|c|c|}
\hline $\mathrm{LL}$ & $\mathrm{LH}$ & \multirow{2}{*}{ LH } & \multirow{3}{*}{ LH } \\
\hline HL & $\mathrm{HH}$ & & \\
\hline \multicolumn{2}{|l|}{ HL } & $\mathrm{HH}$ & \\
\hline \multicolumn{3}{|l|}{ HL } & $\mathrm{HH}$ \\
\hline
\end{tabular}

Fig.3. 3 Level wavelet transform

\section{1) Texture Feature Extraction}

In this paper two wavelet methods i.e. Daubechies and Symtel, were implemented for image retrieval where three wavelet coefficients LH, HL and HH were used. The high level frequency components contain information about edges and high level imaged details, that's why all high level coefficients were taken for matching.

Each image was decomposed into four sub bands and 5 level wavelet transform was performed, and only the detailed coefficient of each level were taken. The approximation coefficient of the image had been ignored.

\section{2) Algorithm For proposed Scheme}

Content based image retrieval system using above two methods i.e. using symtel's wavelet transform and, Daubechies' wavelet transform were implemented through following steps only with the difference that each method used different wavelet transform method as mentioned above.

Step1:

Preprocessing: Each image of the database was resized to a fixed size of $160 \times 120$ pixels.

Step2:

Color feature was extracted by computing color histogram for each of the color plane (red, green, blue) of an image in RGB color space.

Step 3:

Standard deviations of each histogram corresponding to each color plane were computed. Hence each image had three elements for color feature in feature vector.

Step4: To extract texture feature, Daubechies/Symtel wavelet transformation was performed to 5 levels and the coefficient of each level was taken as described in methods above.

Step5:

After getting coefficients, standard deviation of each coefficient is computed for each image of the database.

Step6:

A feature vector was formed with 18 elements out of which 3 elements were based on color feature and 15 elements were based on texture feature. The feature vector was then stored in the database for image retrieval purposes as similarity measure. 
The International Journal of Multimedia \& Its Applications (IJMA) Vol.4, No.4, August 2012

\section{Image Retrieval System Based fuzzy partition of color space}

In this method by partitioning the HSV color space into dominant color bins and by using a specific fuzzy similarity measure, the results show that this approach can contribute to the design of performing automated image retrieval systems. For color image retrieval purposes it is more convenient to use a color model that characterizes color with one dimension instead of three. Therefore, HSV color space is preferred.

The HSV color space (Hue, Saturation and Value) attempts to produce an intuitive representation of color $[13,14]$. Hue is the color as described by wavelength, for instance the distinction between red and yellow. Saturation is the amount of the white light present. The saturation describes how much a certain color differs from white light, for instance the distinction between red (high saturation) and pink (low saturation). The value or intensity is the amount of light, for instance the distinction between dark red and light red or between dark grey and light grey. To produce a color we can simply adjust the hue; to change the amount of white light we adjust the saturation, and to make the color darker or lighter we alter the intensity.

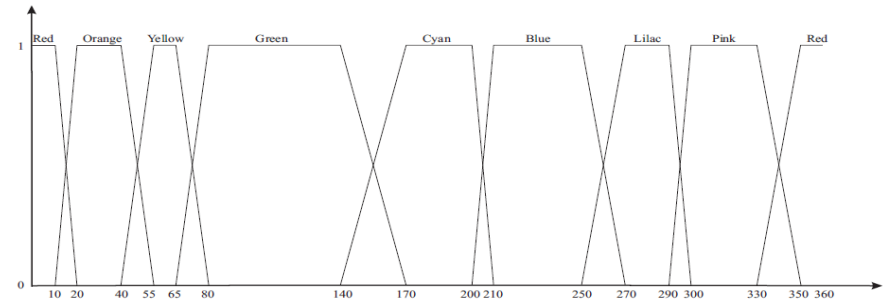

Fig.4. Fuzzy Partition of the hue Component

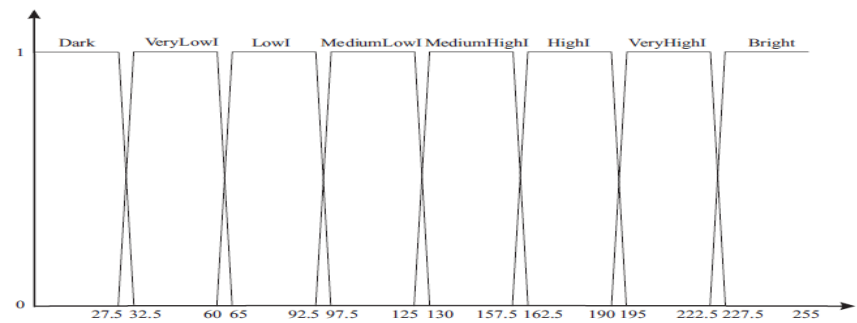

Fig.5. Fuzzy Partition of the value/intensity Component

\section{1) Algorithm For Proposed Scheme}

Content based image retrieval system using Fuzzy partition Daubechies' Wavelet Transform was implemented through following steps:

Step1:

Preprocessing: First of all, each image of the database is resized to fixed size 160x120 pixels. And color space RGB was converted to HSV color space.

Step2:

Fuzzy partition was applied to each of the plane of color space and fuzzy membership function was applied to each pixel.

Step3:

Wavelet transform was performed to 5 levels for each of the plane and the coefficients were calculated.

Step4: 
After getting coefficients, Standard deviation of each coefficient is computed for each image of the database.

Step6:

A feature vector is formed based on these values of standard deviation. The feature vector is then stored in the database for image retrieval purposes.

The HSV color space can be modeled with cylindrical coordinates. The hue is represented as the angle, varying from $0^{\circ}$ to $360^{\circ}$. Saturation corresponds to the radius, varying from 0 to 1 (or from 0 to 255). The value or intensity varies along the z-axis with 0 being black and 1 (or 255) being white. Therefore, the HSI color space is very suitable, since the hue component is enough to recognize the color. In those cases where there is nearly no color present in the image we will use the intensity component to identify the dominant "color". For Hue and Value components fuzzy partition [8] was used to model the components which are shown in figure 4(hue component) and figure 5(value/intensity component).

A fuzzy set $A[15]$ in a universe $X$ is characterized by a $X-[0,1]$ mapping $X_{A}$, which associates with every element $x$ in $X$ a degree of membership $X_{A}(x)$ of $x$ in the fuzzy set $A$ [8]. A trapezoidal fuzzy number $\mathrm{A}[8,16]$ is a fuzzy set with a trapezoidal-shaped membership function.

\section{Image Retrieval System Based curvelet transform}

Basically, curvelet transform extends the ridgelet transform to multiple scale analysis. Curvelet transform is generally based on wrapping of Fourier samples takes a 2-D image as input in the form of a Cartesian array $f[m, n]$ such that $0 \leq m<M, 0 \leq n<N$ and generates a number of curvelet coefficients indexed by a scale $j$, an orientation $l$ and two spatial location parameters $(k$, $k_{2}$ ) as output[10]. Statistical operations are applied to these coefficients to form the curvelet texture descriptor. Discrete curvelet coefficients can be defined by following equation:

$$
C^{D}\left(j, l, k_{1}, k_{2}\right)=\sum f[m, n] \phi_{j, l, k_{1}, k_{2}}^{D}[m, n]
$$

Here, each $\phi_{\mathrm{j}, \mathrm{l}, \mathrm{k}_{1}, \mathrm{k}_{2}}^{\mathrm{D}}[\mathrm{m}, \mathrm{n}]$ is a digital curvelet waveform. The digital curvelet transform is implemented using the fast discrete curvelet transform. Given an image, both the image and the curvelet are transformed into Fourier domain, and then the convolution of the curvelet with the image in spatial domain becomes the product in Fourier domain. Finally the curvelet coefficients are obtained by applying inverse Fourier transform on the spectral product. Once the curvelet coefficients have been obtained, the mean and standard deviation are computed as the texture features for the curvelet. A rectangular frequency tiling that covers the whole image in the spectral domain is represented by Figure 6 .

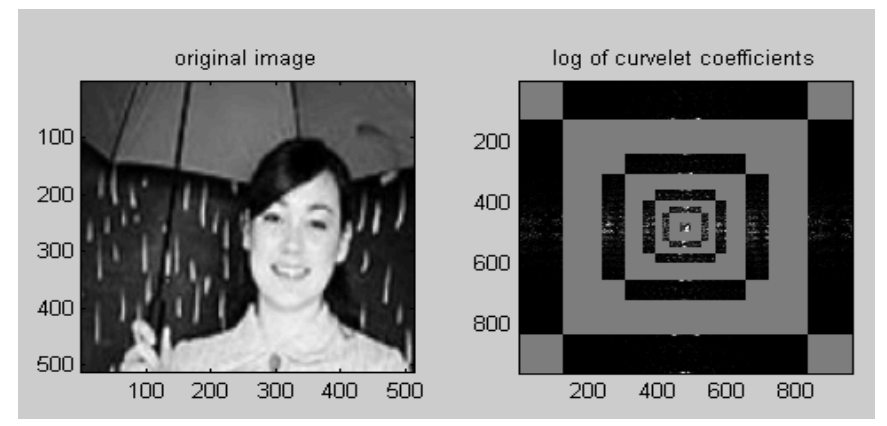

Fig.6. Curvelet coefficient of an image 
The International Journal of Multimedia \& Its Applications (IJMA) Vol.4, No.4, August 2012

In this paper, the performance of the curvelet feature in terms of retrieval accuracy was analyzed. The database consists of 12 different categories of natural texture images, each image has the same size of $512 \times 512$ pixel .The 5 level curvelet transform was performed and the curvelet feature was extracted using the process described above to each of the images in the database . for 5 levels analysis, $42(=1+8+16+16+1)$ subbands of curvelet coefficients are computed and all were combined together into a single coefficient matrix. Once the curvelet coefficient was computed of each image, its standard deviation and mean were calculated and stored in database. The curvelet coefficient along with the wavelet coefficient and color feature was used to index each image of the database. Finally images were retrieved based on these feature vectors using Euclidean distance.

\section{SIMILARITY MEASURE}

Content-based image retrieval determines visual similarities between a query image and images in a database. Different similarity measures will affect retrieval performances of an image retrieval system significantly. In this paper three different distance metric to measures were used and the performance evaluated by each method .Canberra and Euclidean distance, both measures were used for finding similar images. Euclidean distance is used for all three methods between the standard deviations of the query image and the images in the database.

Euclidean distance $=\sqrt{\sum\left(a_{i}-b_{i}\right)^{2}}$

Canberra distance $=\sum\left|a_{i}-b_{i}\right| /\left|a_{i}\right|+\left|b_{i}\right|$

\section{EXPERIMENTAL RESULTS}

Around 1000 images were used in the database, which consists of 12 different categories namely red rose, bird, sunflower, girl, aquarium, car, girl in rain, starfish, baby, tiger, horse and oranges. Out of these 12 categories of images, the results of tiger and bird are shown below. In each of the results shown below the top middle of the window shows the query image.

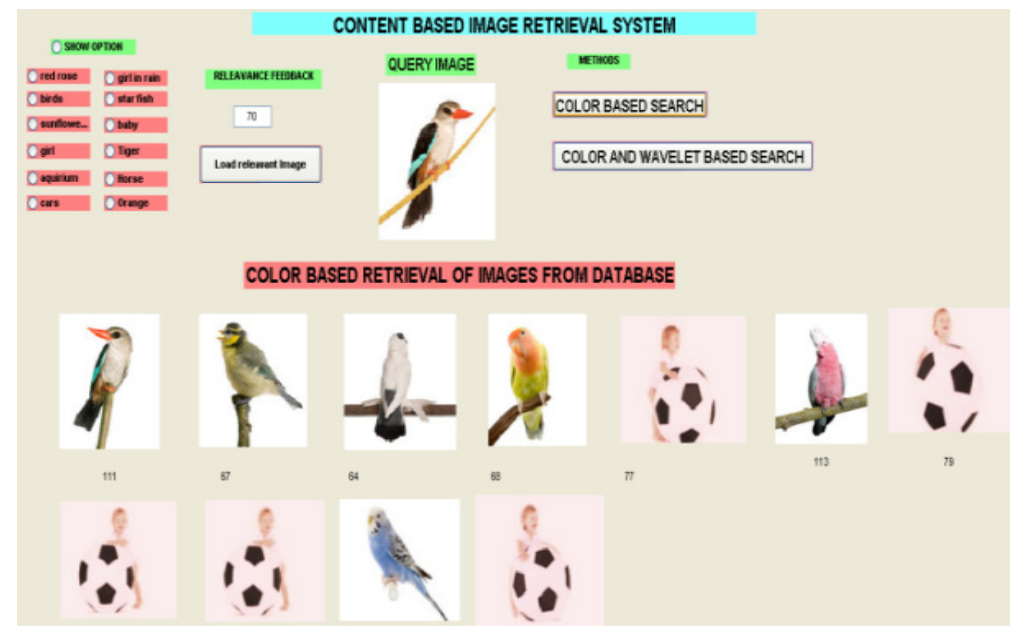

Fig.7 (a). Results of HSV Color Based Method 
The International Journal of Multimedia \& Its Applications (IJMA) Vol.4, No.4, August 2012

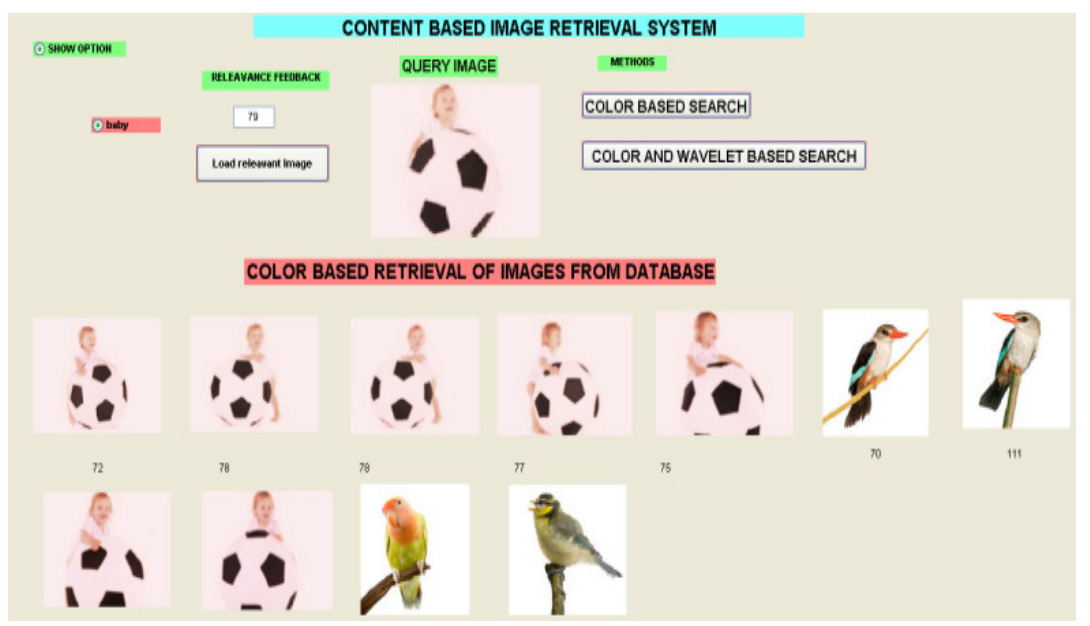

Fig.7 (b). Results of HSV Color Based Method

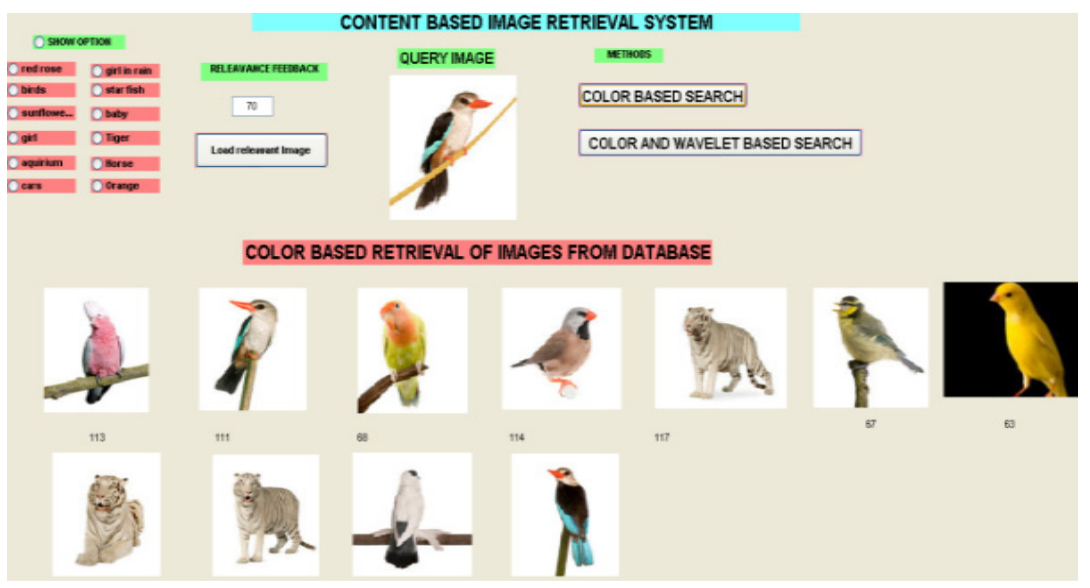

Fig.8. (a) Results of YCbCr Color Based Method

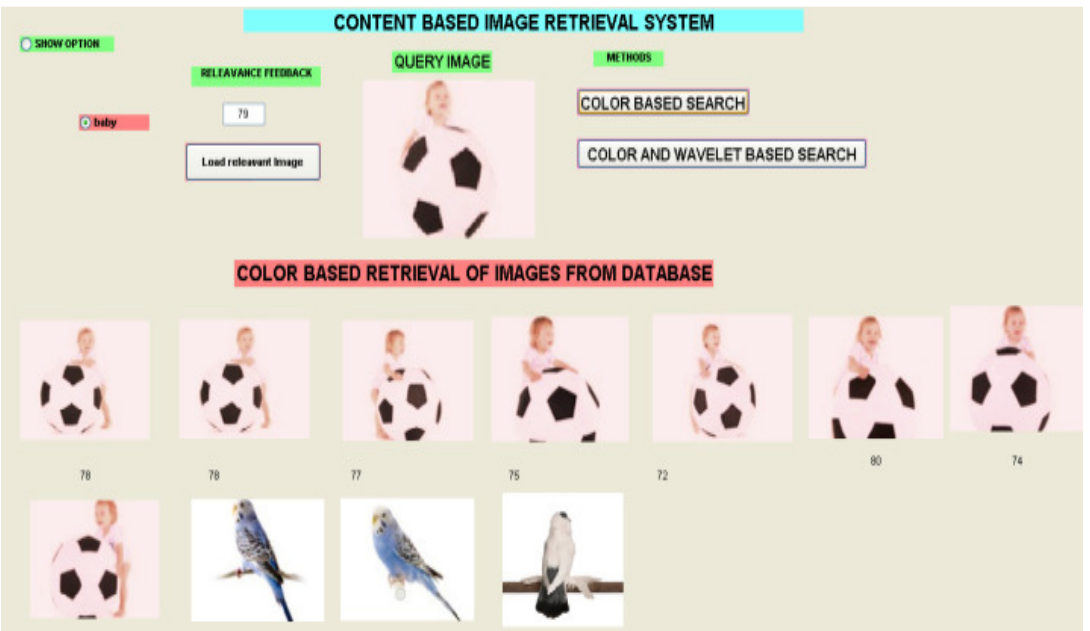

Fig.8. (b) Results of YCbCr Color Based Method 
The International Journal of Multimedia \& Its Applications (IJMA) Vol.4, No.4, August 2012

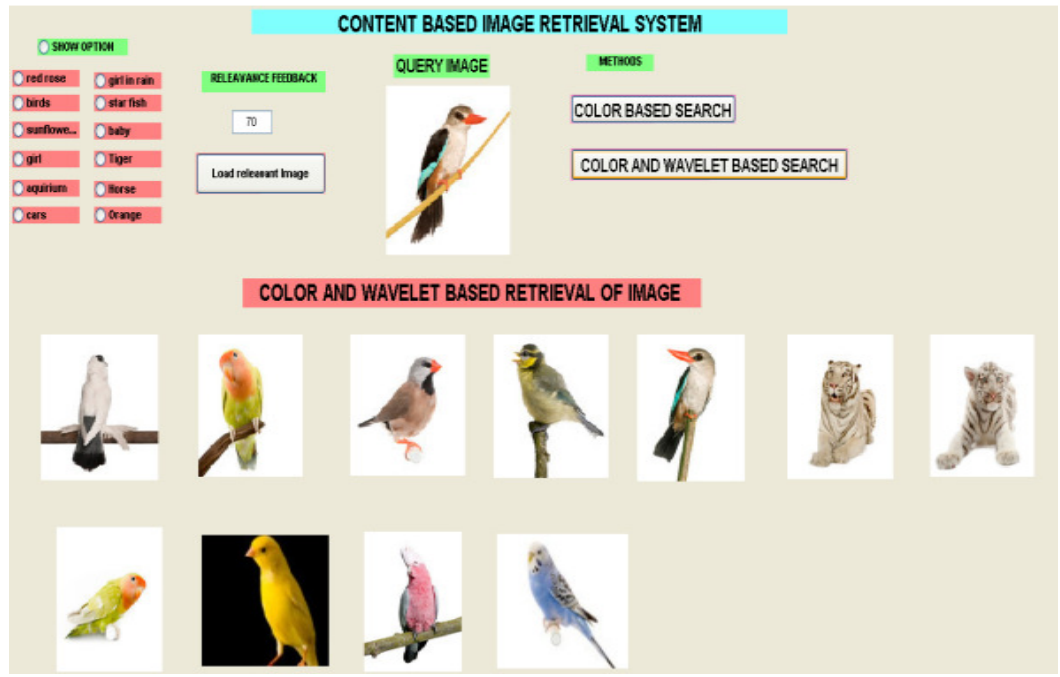

Fig.9. (a) Results of Symtel Wavelet Transform Method

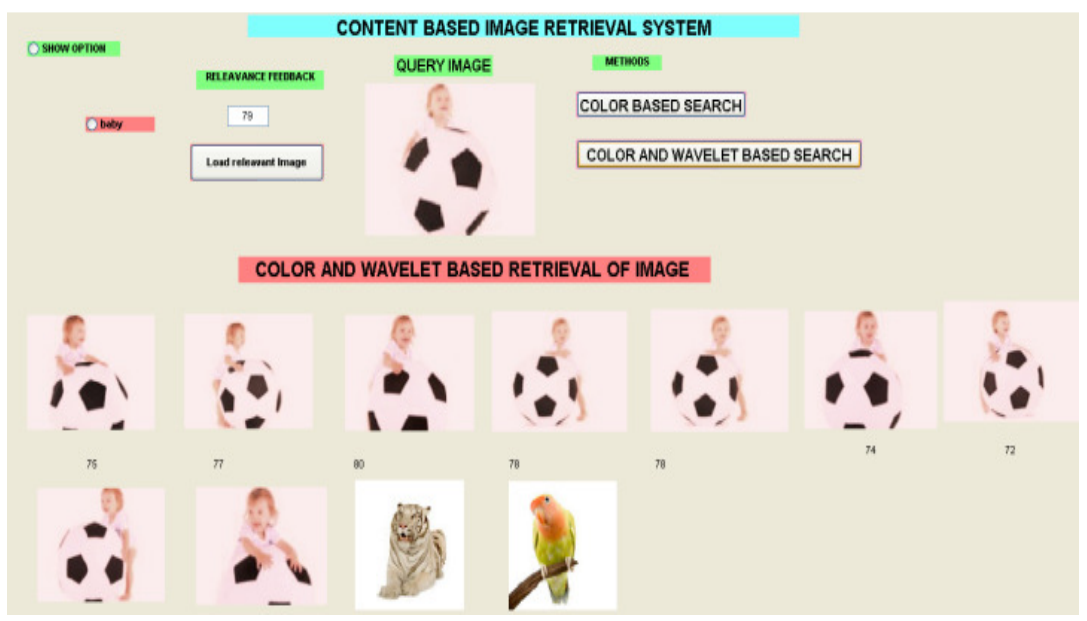

Fig.9. (b) Results of Symtel Wavelet Transform Method

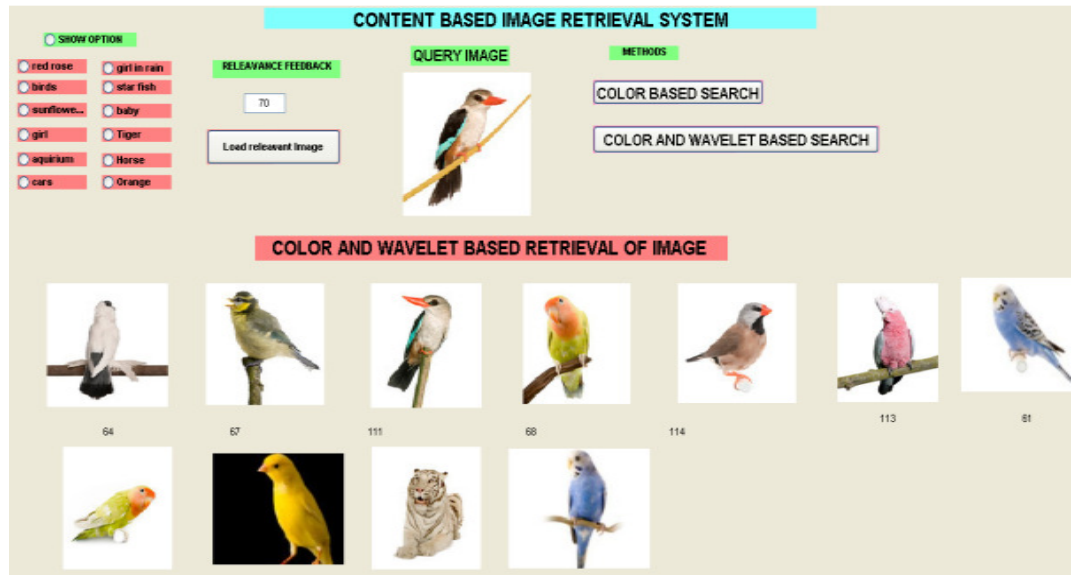

Fig.10. (a) Results of Daubechies Wavelet Transform Method 
The International Journal of Multimedia \& Its Applications (IJMA) Vol.4, No.4, August 2012

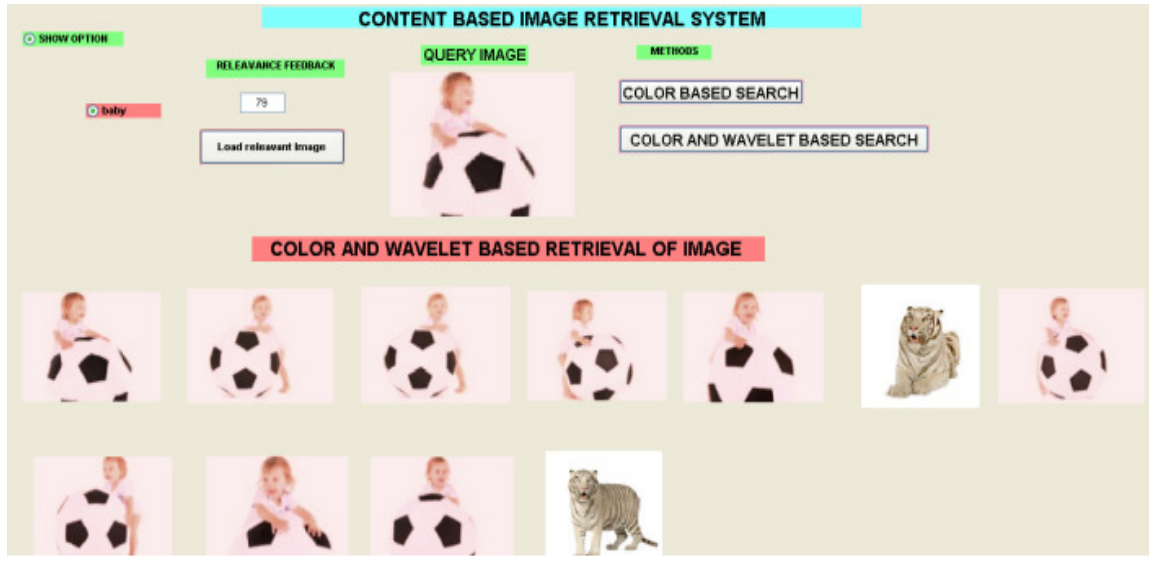

Fig.10. (b) Results of Daubechies Wavelet Transform Method

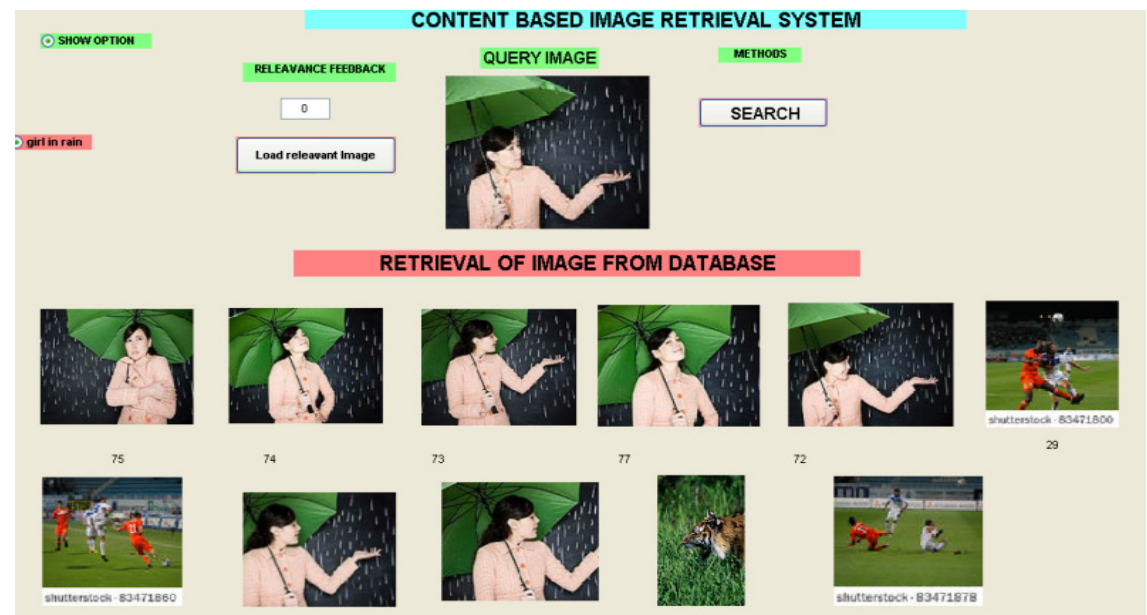

Fig.11. (a): Fuzzy Partition Based Method

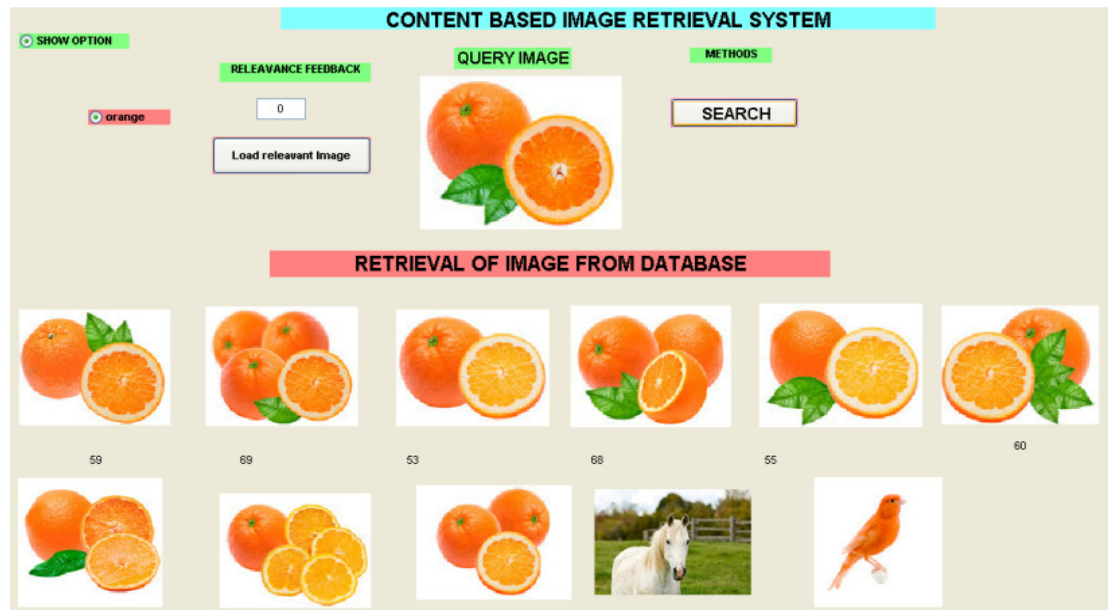

Fig.11. (b): Fuzzy Partition Based Method 
The International Journal of Multimedia \& Its Applications (IJMA) Vol.4, No.4, August 2012

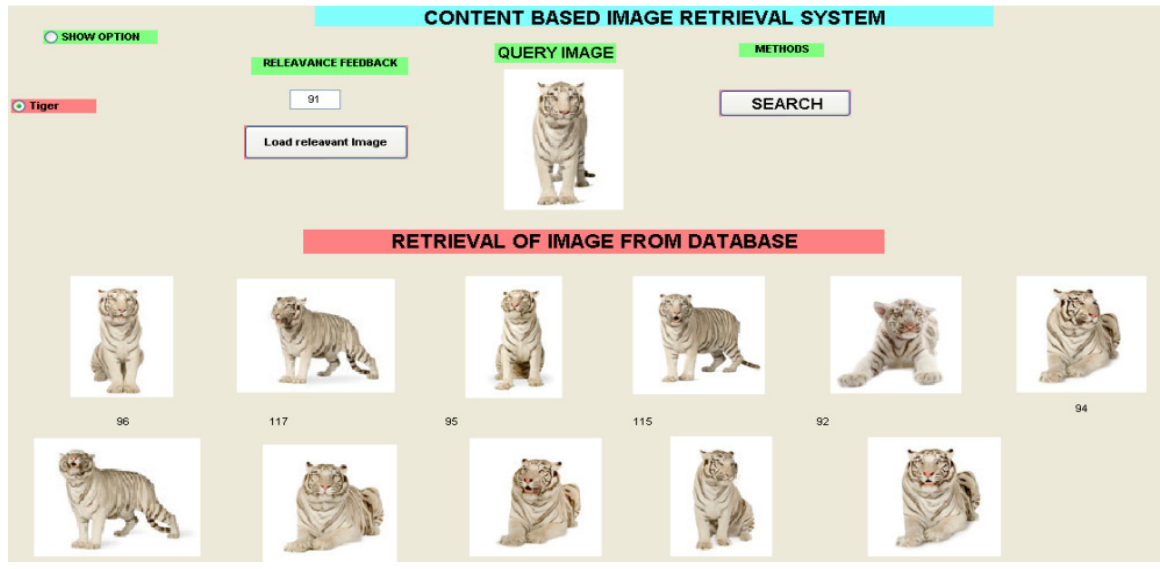

Fig.12. (a): Curvelet Transform Method

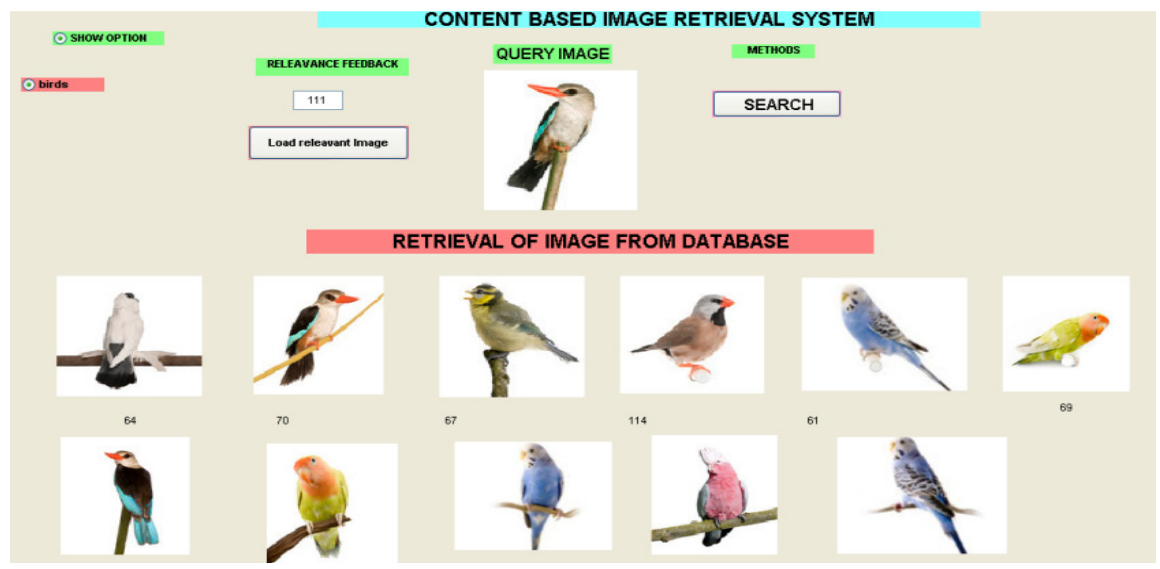

Fig.12. (b): Curvelet Transform Method

Performance comparison of content-based image retrieval systems is a crucial and non-trivial task since it is very difficult to determine the relevant sets. The commonly used performance measurement parameters for the evaluation of retrieval performance are, precision and recall [1]. Precision $P$ measures the accuracy of the retrieval. Precision $P$ is defined as the ratio of the number of retrieved relevant images to the total number of retrieved images. Recall $\mathrm{R}$ measures the robustness of the retrieval. Recall $\mathrm{R}$ is defined as the ratio of the number of retrieved relevant images to the total number of relevant images in the whole database.

The performance and efficiency measurement of all the techniques were computed to give a brief comparison between the systems through Precision and recall. Precision and recall is given as follows: 
The International Journal of Multimedia \& Its Applications (IJMA) Vol.4, No.4, August 2012

$$
\begin{aligned}
& \text { Precision }(\mathrm{P})=\quad \frac{\text { Total number of retrieved relevant images }}{\text { Total number of retrieved images }} \\
& \text { Recall }(\mathrm{R})=\quad \frac{\text { Total number of retrieved relevant images }}{\text { Total number of relevant images in the database }} \\
& \text { Accuracy }=\quad \text { (Precision }+ \text { Recall) } / 2
\end{aligned}
$$

As the whole database was known, every image of the database was used as query image. For each query image both precision and recall values were obtained. Finally the average value of precision and recall were obtained for each category of images of the database for all techniques and results for both Euclidean distance and Canberra distance are shown below in table 1 and table 2. The average percentage of accuracy for each category of images are shows in table 4 and table 5 and the percentage of accuracy of each method for all two similar measurement metrics are shown in table 3.

Table 1 Average percentage recall for all methods

\begin{tabular}{|c|c|c|c|c|}
\hline $\begin{array}{c}\text { Distance } \\
\text { Metrics }\end{array}$ & $\begin{array}{c}\text { Color } \\
\text { Based } \\
\text { Search } \\
\text { (HSV) }\end{array}$ & $\begin{array}{c}\text { Color } \\
\text { Based } \\
\text { Search } \\
\text { (YCbCr) }\end{array}$ & $\begin{array}{c}\text { Color and } \\
\text { wavelet } \\
\text { Based } \\
\text { Search } \\
\text { (Symtel) }\end{array}$ & $\begin{array}{c}\text { Color and } \\
\text { wavelet Based } \\
\text { Search }\end{array}$ \\
(Daubechies)
\end{tabular}

Table 2 Average percentage precision for all methods

\begin{tabular}{|c|c|c|c|c|}
\hline $\begin{array}{c}\text { Distance } \\
\text { Metrics }\end{array}$ & $\begin{array}{c}\text { Color } \\
\text { Based } \\
\text { Search } \\
\text { (HSV) }\end{array}$ & $\begin{array}{c}\text { Color } \\
\text { Based } \\
\text { Search } \\
\text { (YCbCr) }\end{array}$ & $\begin{array}{c}\text { Color } \\
\text { and } \\
\text { Wavelet } \\
\text { Based } \\
\text { Search }\end{array}$ & $\begin{array}{c}\text { Color and } \\
\text { Wavelet } \\
\text { Based Search } \\
\text { (Daubechies) }\end{array}$ \\
\hline $\begin{array}{c}\text { Euclidean } \\
\text { distance }\end{array}$ & 72.66 & 76.66 & 84 & 84.83 \\
\hline $\begin{array}{c}\text { Canberra } \\
\text { distance }\end{array}$ & 70 & 74.25 & 75.83 & 78.41 \\
\hline
\end{tabular}


The International Journal of Multimedia \& Its Applications (IJMA) Vol.4, No.4, August 2012

Table 3 Average percentage of accuracy all mehods

\begin{tabular}{|c|c|c|c|c|}
\hline $\begin{array}{c}\text { Distance } \\
\text { Metrices }\end{array}$ & $\begin{array}{c}\text { Color } \\
\text { Based } \\
\text { Search } \\
\text { (HSV) }\end{array}$ & $\begin{array}{c}\text { Color } \\
\text { Based } \\
\text { Search } \\
\text { (YCbCr) }\end{array}$ & $\begin{array}{c}\text { Color } \\
\text { and } \\
\text { Wavelet } \\
\text { Based } \\
\text { Search } \\
\text { (Symtel) }\end{array}$ & $\begin{array}{c}\text { Color and } \\
\text { Wavelet Based } \\
\text { Search } \\
\text { (Daubechies) }\end{array}$ \\
\hline $\begin{array}{c}\text { Euclidean } \\
\text { distance }\end{array}$ & 66.3 & 70.5 & 76.62 & 78.25 \\
\hline $\begin{array}{c}\text { Canberra } \\
\text { distance }\end{array}$ & 64.5 & 68.37 & 69.93 & 71.2 \\
\hline
\end{tabular}

Table 4 Percentage of accuracy for each category of images for Euclidean distance

\begin{tabular}{|c|c|c|c|c|}
\hline Image & $\begin{array}{c}\text { Color } \\
\text { Sased } \\
\text { Search } \\
\text { Category }\end{array}$ & $\begin{array}{c}\text { Color Based } \\
\text { Search } \\
(\text { YCbCr) }\end{array}$ & $\begin{array}{c}\text { Color and } \\
\text { Wavelet Based } \\
\text { Search } \\
\text { (Symtel) }\end{array}$ & $\begin{array}{c}\text { Color and } \\
\text { Wavelet Based } \\
\text { Search } \\
\text { (Daubechies) }\end{array}$ \\
\hline Red Rose & 84 & 70.5 & 71.5 & 72.5 \\
\hline Bird & 55 & 66.5 & 70.5 & 74.5 \\
\hline Sunflower & 41 & 83 & 89.5 & 93.5 \\
\hline Girl & 76 & 72.5 & 69.5 & 72.5 \\
\hline Aquarium & 80 & 68.5 & 95 & 95 \\
\hline Car & 59 & 72.5 & 95 & 95 \\
\hline Girl in rain & 69.5 & 34.5 & 64 & 64 \\
\hline Starfish & 85.5 & 64 & 87.5 & 87.5 \\
\hline Baby & 49.5 & 84 & 86.5 & 86.5 \\
\hline Tiger & 77 & 78.5 & 78.5 & 78.5 \\
\hline Horse & 48.5 & 73.5 & 54.5 & 57 \\
\hline Oranges & 77 & 78.5 & 57.5 & 62.5 \\
\hline
\end{tabular}


The International Journal of Multimedia \& Its Applications (IJMA) Vol.4, No.4, August 2012

Table 4 Percentage of accuracy for each category of images for Canberra distance

\begin{tabular}{|c|c|c|c|c|}
\hline $\begin{array}{l}\text { Image } \\
\text { Category }\end{array}$ & $\begin{array}{l}\text { Color } \\
\text { Based } \\
\text { Search } \\
\text { (HSV) }\end{array}$ & $\begin{array}{l}\text { Color } \\
\text { Based } \\
\text { Search } \\
\text { (YCbCr) }\end{array}$ & $\begin{array}{c}\text { Color and } \\
\text { Wavelet Based } \\
\text { Search } \\
\text { (Symtel) }\end{array}$ & $\begin{array}{c}\text { Color and } \\
\text { Wavelet Based } \\
\text { Search } \\
\text { (Daubechies) }\end{array}$ \\
\hline Red Rose & 81 & 70.5 & 70.5 & 71.5 \\
\hline Bird & 55 & 64 & 60.3 & 61.5 \\
\hline Sunflower & 61 & 64 & 66.5 & 68 \\
\hline Girl & 73.5 & 74.5 & 79 & 79 \\
\hline Aquarium & 74.5 & 70.5 & 77 & 80 \\
\hline Car & 61 & 95 & 95 & 95 \\
\hline Girl in rain & 61 & 38 & 41.2 & 42.6 \\
\hline Starfish & 72.5 & 52.5 & 76 & 76 \\
\hline Baby & 45 & 81 & 69.3 & 71 \\
\hline Tiger & 45 & 74.5 & 77.5 & 79.5 \\
\hline Horse & 76 & 64 & 64 & 66.5 \\
\hline Oranges & 68.5 & 72 & 63.1 & 64.5 \\
\hline
\end{tabular}

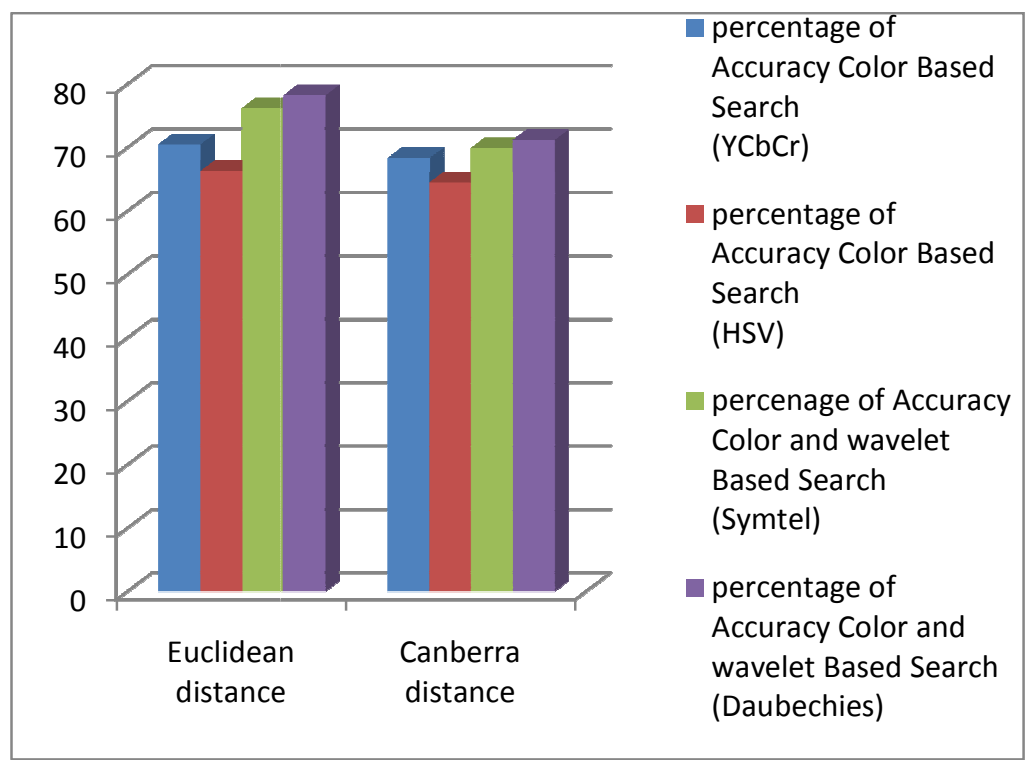

Fig.13. Represents the table 3 in bar graph 
The International Journal of Multimedia \& Its Applications (IJMA) Vol.4, No.4, August 2012

From the above tables, it is clear that the performance of Euclidean distance is better as compare to the canberra distance, Hence we perform the rest methods only using Euclidean distance. The Table 5 represents the accuracy for each image in database for both fuzzy partition and curvelet based method. The following Table 6 shows the percentage of accuracy for fuzzy partition and curvelet transform method along with all previous methods.

TABLE 5: Percentage of Accuracy for Each Category of Images for Euclidean Distance

\begin{tabular}{|c|c|c|}
\hline Image Category & $\begin{array}{c}\text { Fuzzy Partition Based } \\
\text { Search }\end{array}$ & Curvelet Based Search \\
\hline Red Rose & 72 & 78.1 \\
\hline Bird & 71.4 & 78 \\
\hline Sunflower & 89 & 95 \\
\hline Girl & 70.5 & 71.5 \\
\hline Aquarium & 95 & 95 \\
\hline Car & 93.5 & 95 \\
\hline Girl in rain & 63 & 68.6 \\
\hline Starfish & 87.5 & 88.65 \\
\hline Baby & 86 & 88.6 \\
\hline Tiger & 78.5 & 82 \\
\hline Horse & 55 & 68 \\
\hline Oranges & 57.5 & 65 \\
\hline
\end{tabular}

TABLE 4.11: Average Percentage of Accuracy All Method

\begin{tabular}{|c|c|c|c|c|c|c|}
\hline $\begin{array}{c}\text { Distance } \\
\text { Matrices }\end{array}$ & $\begin{array}{c}\text { Color } \\
\text { Based } \\
\text { Search } \\
\text { (HSV) }\end{array}$ & $\begin{array}{c}\text { Color } \\
\text { Based } \\
\text { Search } \\
\text { (YCbCr) }\end{array}$ & $\begin{array}{c}\text { Color } \\
\text { and } \\
\text { wavelet } \\
\text { Based } \\
\text { Search } \\
\text { (Symtel) }\end{array}$ & $\begin{array}{c}\text { Color and } \\
\text { wavelet Based } \\
\text { Search } \\
\text { (Daubechies) }\end{array}$ & $\begin{array}{c}\text { Fuzzy } \\
\text { Partition } \\
\text { Based } \\
\text { Search }\end{array}$ & $\begin{array}{c}\text { Curvelet } \\
\text { Based } \\
\text { Search }\end{array}$ \\
\hline $\begin{array}{c}\text { Euclidean } \\
\text { distance }\end{array}$ & 66.3 & 70.5 & 76.62 & 78.25 & 75.24 & 81.165 \\
\hline
\end{tabular}

\section{CONCLUSIONS}

The main objective of this research is to investigate and evaluate an effective and robust approach for texture representation and to use it in image retrieval. For this purpose, we have investigated the texture analysis using several approaches. Throughout the contrast, the characteristics of the main MR methods, i.e., discrete wavelet, and discrete curvelet were discussed. Discrete curvelet transform has absorbed the advantages of both the color feature and wavelet while overcomes the disadvantages of both these methods. From experimental results, the curvelet texture features are found to be promising. Finally, we compared the curvelet CBIR performance with that of the existing color based methods and wavelet based methods. This research has found that curvelet features outperformed the existing texture features in both accuracy and efficiency. 
The International Journal of Multimedia \& Its Applications (IJMA) Vol.4, No.4, August 2012

From all the experimental results, HSV color space based search gives an average retrieval accuracy of $66.3 \%$, YCbCr color space based search gives an average retrieval accuracy of $70.5 \%$, Fuzzy partitioned based search gives an average retrieval accuracy of $75.24 \%$, Symtel wavelet based search gives an average retrieval accuracy of $76.62 \%$ and Daubechies wavelet based search gives an average retrieval accuracy of $78.25 \%$ and for Euclidean distance measurement. Finally curvelet based search gives an average retrieval accuracy of $81.165 \%$. Performance of curvelet based search is better than the wavelet and color based search because the curvelet captures edge information more accurately than wavelet. Therefore, we find discrete curvelet texture descriptor as a powerful means to perform CBIR.

\section{References}

[1] Sharma,N., Rawat, P., and Singh,J., Efficient CBIR Using Color Histogram Processing, Signal \& Image Processing: An International Journal(SIPIJ) Vol.2, No.1,( March 2011).

[2] Dubey,R., Choubey,R., Dubey,S., Efficient Image Mining using Multi Feature Content Based Image Retrieval System, Int Jr of Advanced Compute Engineering and Architecture Vol. 1, (June 2011).

[3] Khan,W., Kumar,S., Gupta,N., Khan,N., A Proposed Method for Image Retrieval using Histogram values and Texture Descriptor Analysis, IJSCE, ISSN: 231-2307, Volume-I Issue-II,( May 2011).

[4] Vadivel,A., Majumdar,A.K., and Sural,S., Image Retrieval using Wavelet Based Texture Features, International Conference on Communications, Devices and Intelligent Systems, (2004).

[5] Brodatz,P., Textures: A Photographic Album for Artists and Designers, New York, Dover , (1966).

[6] Vadivel,A., .Majumdar,A.K.,and Sural,S., Characteristics of Weighted Feature Vector in ContentBased Image Retrieval Applications, (2000).

[7] Suhasini, P.S., Krishna,K.S.R, Krishna,V.M., CBIR Using Color Histogram Processing, Journal Theoretical and Applied Information technology, (NWTIT), page 110-115.

[8] Nachtegaela, M., Wekenb, D. V., Wittea, V. D., Schultea, S., M'elangea, T., Kerrea, E.E., Color Image Retrieval Using Fuzzy Similarity Measures And Fuzzy Partitions, ICIP, IEEE(2007).

[9] Ni L. and Leng H C, Curvelet Transform and Its Application in Image Retrieval, $3^{\text {rd }}$ International Symposium on Multispectral Image Processing and Pattern Recognition, Proceedings of SPIE, 5286,(2003).

[10] Sumana, Islam M, Zhang D S and Lu G, Content Based Image Retrieval Using Curvelet Transform. In Proc. of IEEE International Workshop on Multimedia Signal Processing (MMSP08), Cairns, Queensland, Australia, ISBN 978-1-4244-2295-1:11- 16,(2008).

[11] Khan,W., Kumar,S., Gupta,N., Khan,N., Signature Based Approach For Image Retrieval Using Color Histogram And Wavelet Transform, International Journal of Soft Computing and Engineering (IJSCE), (March 2011).

[12] Ali,A., Murtaza,S., Malik,A.S., Content Based Image Retrieval Using Daubechies Wavelet Transform, Proceedings of the $2^{\text {nd }}$ National Workshop on Trends in Information Technology, (2003).

[13] Sharma, G., Digital color imaging handbook, CRC Press, (2003). 
The International Journal of Multimedia \& Its Applications (IJMA) Vol.4, No.4, August 2012

[14] Russ, J.C., The image processing handbook, CRC Press, (1999).

[15] Zadeh, L.A., Fuzzy sets, Information Control, Vol. 8, pp. 338-353, (1965).

[16] Fuller, R., On product-sum of triangular fuzzy numbers, Fuzzy Sets and Systems, Vol. 41, No. 1, pp. 83-87, (1991). 